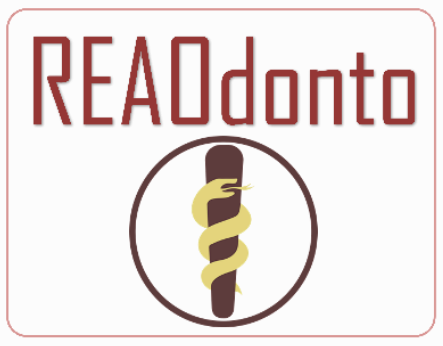

Revista Eletrônica Acervo Odontológico

\section{ARTIGO ORIGINAL}

Recebido em: 12/2020

Aceito em: $1 / 2021$

Publicado em: 4/2021

\title{
Efeitos de extrato em gel de chenopodium ambrosioides I. (mastruz) no tratamento de lesões ósseas de ratas osteoporóticas
}

\author{
Effects of chenopodium ambrosioides I. (mastruz) gel extract in the treatment of bone \\ lesions in osteoporotic rats
}
Efectos del extracto en gel de chenopodium ambrosioides I. (mastruz) sobre el tratamiento de las lesiones óseas de ratas osteoporóticas

Gustavo Diniz Trindade ${ }^{1 *}$, Antônio Luiz Martins Maia Filho², Jairelda Sousa Rodrigues ${ }^{1}$, Daniel Cabral Leão Ferreira ${ }^{2}$, Karinne Sousa de Araújo'.

\begin{abstract}
Resumo: O objetivo foi produzir extrato em gel de Chenopodium ambrosioides e analisar os efeitos do uso tópico no reparo ósseo de ratas osteoporóticas, realizando triagem fitoquímica para identificação de taninos e saponinas, verificando microscopicamente o processo inflamatório durante a reparação e neoformação óssea pós-lesão. Para produzir o extrato de mastruz utilizou-se folhas frescas. Após trituração o líquido foi incorporado ao carbopol para obter consistência gelatiniforme. Para analisar os efeitos do extrato em gel foram utilizadas 12 ratas Wistar com osteoporose induzida, divididas em dois grupos. No grupo 1, o defeito ósseo foi preenchido por coágulo sanguíneo; e no grupo 2, com gel do extrato de mastruz. Por triagem fitoquímica identificou-se taninos e saponinas no extrato em gel de mastruz. Aos 30 dias, no grupo 1, observou-se leve infiltrado inflamatório preenchido por espículas ósseas delgadas e intercomunicantes formadas por tecido ósseo primário. No grupo 2, identificou-se formação de trabeculado ósseo espesso constituído por tecido ósseo primário e secundário, com defeito ósseo recoberto por periósteo e ausência de sinais inflamatórios. Foi produzido extrato em gel de mastruz gelatinoso com presença de taninos e saponinas, identificados por triagem fitoquímica, mostrando-se favorável na reparação óssea em defeitos cirúrgicos realizados nas tíbias das ratas osteoporóticas.
\end{abstract}

Palavras-chave: Chenopodium ambrosioides, Osteoporose, Ovariectomia.

\begin{abstract}
The objective was to produce Chenopodium ambrosioides gel extract and analyze the effects of topical use on bone repair in osteoporotic rats, performing phytochemical screening to identify tannins and saponins, microscopically verifying the inflammatory process during bone repair and post-injury neoformation. Fresh leaves were used to produce the mastruz extract. After crushing, the liquid was incorporated into the carbopol to obtain gelatiniform consistency. To analyze the effects of the gel extract, 12 Wistar rats with induced osteoporosis were used, divided into two groups. In group 1, the bone defect was filled by a blood clot; and in group 2, with gel of the mast extract. By phytochemical screening, tannins and saponins were identified in the gel extract of the mast. At 30 days, in group 1, there was a mild inflammatory infiltrate filled with thin and intercommunicating bone spicules formed by primary bone tissue. In group 2, the formation of thick bony trabecular tissue was identified, consisting of primary and secondary bone tissue, with bone defect
\end{abstract}

\footnotetext{
1 UniFacid Wyden, Teresina - PI. *E-mail: gustavo.dt@hotmail.com
}

2 Universidade Estadual do Piauí (UESPI), Teresina - PI. 
covered by periosteum and absence of inflammatory signs. A gelatinous mast gel extract was produced with the presence of tannins and saponins, identified by phytochemical screening, showing a favorable bone repair in surgical defects performed on the tibias of osteoporotic rats.

Key words: Chenopodium ambrosioides, Osteoporosis, Ovariectomy.

Resumen: El objetivo fue producir extracto de gel de Chenopodium ambrosioides y analizar los efectos del uso tópico en la reparación ósea en ratas osteoporóticas, realizando un cribado fitoquímico para identificar taninos y saponinas, verificando microscópicamente el proceso inflamatorio durante la reparación ósea y la neoformación poslesión. Se utilizaron hojas frescas para producir el extracto de mastruz. Después de triturar, el líquido se incorporó al carbopol para obtener una consistencia gelatiniforme. Para analizar los efectos del extracto en gel se utilizaron 12 ratas Wistar con osteoporosis inducida, divididas en dos grupos. En el grupo 1, el defecto óseo fue llenado por un coágulo de sangre; y en el grupo 2, con gel del extracto de mástil. Mediante cribado fitoquímico, se identificaron taninos y saponinas en el extracto de gel del mástil. A los 30 días, en el grupo 1, había un infiltrado inflamatorio leve relleno de espículas óseas delgadas e intercomunicadas formadas por tejido óseo primario. En el grupo 2 se identificó la formación de tejido trabecular óseo grueso, constituido por tejido óseo primario y secundario, con defecto óseo cubierto por periostio y ausencia de signos inflamatorios. Se elaboró un extracto gelatinoso de mástil con presencia de taninos y saponinas, identificados mediante cribado fitoquímico, que muestra una reparación ósea favorable en defectos quirúrgicos realizados en tibias de ratas osteoporóticas.

Palabras clave: Chenopodium ambrosioides, Osteoporosis, Ovariectomia.

\section{INTRODUÇÃO}

O tecido ósseo é o principal componente do sistema esquelético servindo de suporte para os tecidos moles, como os músculos esqueléticos; desempenha papel de reservatório de cálcio e fosfato para o organismo; além de proteção de órgãos vitais, como os que se encontram dentro do tórax e crânio. Essa capacidade multifuncional do tecido ósseo está relacionada com as particularidades da sua matriz mineralizada, a qual the confere plasticidade e rigidez (MARQUES L, 2017). No interior dessa matriz encontram-se íons cálcio e fósforo organizados na forma de cristais de hidroxiapatita, o que confere ao tecido ósseo capacidade de resistir a fortes cargas e pressões e também tem a importante função de homeostase do cálcio e fosfato, haja vista a função de reservatório mineral a qual o osso possui (FENG X e McDONALD JM, 2011).

O reparo ósseo faz-se por neoformação do tecido ósseo que une as partes fraturadas, ocorrendo remodelação e formação de tecido ósseo igual ao tecido perdido na fratura. Semelhante ao que ocorre na cicatrização, há dois tipos de reparo de fraturas: reparo primário (quando as extremidades fraturadas estão justapostas e com um mínimo espaço entre elas) e secundário (quando há um espaçamento maior entre as extremidades fraturadas, onde um coágulo resultante da hemorragia ocupa tal espaço) (FILHO GB, 2011). Imediatamente após o trauma ósseo, ocorre a ruptura do periósteo e endósteo, consequentemente vasos sanguíneos são rompidos e promovem uma hemorragia local, formando um hematoma e preenchendo a cavidade por coágulo sanguíneo, que servirá de estrutura para maturação do calo ósseo cicatricial (SCHROEDER JE e MOSHEIFF R, 2011). Na área da lesão inicia uma resposta inflamatória necessária para o processo de cicatrização (PUZIPE KTP, 2016)

A osteoporose, definida como distúrbio osteometabólico de origem multifatorial (SARTORI AR, et al., 2008) e que é considerada um problema de saúde pública, haja vista a ocorrência em pelo menos $30 \%$ das mulheres após a menopausa (LESLIE WD e MORIN SN, 2014). A densidade e a forma do tecido ósseo são mantidas ao longo da vida por um equilíbrio entre os aspectos fisiológicos e mecânicos (PEREIRA SEM e MENDONÇA LMC, 2002). Porém, no caso de osteoporose, os prejuízos ao tecido ósseo são devido a diminuição da atividade dos osteoblastos e aumento da atividade dos osteoclastos, pois, tal doença causa a redução da 
massa esquelética e a deterioração da microarquitetura do osso, causando fragilidade e elevando o risco de fraturas (SOARES CD, et al., 2015; SILVA E, 2012).

Em diversas regiões do Brasil é comum a utilização de plantas e ervas medicinais para os mais diversos fins. Várias espécies vegetais são amplamente utilizadas para a cicatrização de feridas devido suas propriedades terapêuticas, como é o caso do mastruz, cientificamente nomeado de Chenopodium ambrosioides (SÉRVIO EML, et al., 2011). O tratamento de feridas com extrato de mastruz não demonstra capacidade de alterar os níveis séricos de cálcio, fósforo e magnésio acreditando que o mecanismo de ação de tal erva medicinal seja a nível celular, ativando osteoblastos e inibindo osteoclastos, ao invés de minerais metabolizantes (SOARES CD, et al., 2015). O uso de agentes fitoterápicos apresenta vantagens importantes como baixo custo, alta disponibilidade e poucos efeitos adversos quando comparados às drogas (PENHA ES, et al., 2017).

Diante do contexto, este trabalho visa produzir um extrato em gel de Chenopodium ambosioides (mastruz) para utilização tópica em defeitos ósseos experimentais, realizando a triagem fitoquímica para identificação de taninos e saponinas na sua composição e averiguando os efeitos do extrato em gel de Chenopodium ambrosioides (mastruz) no reparo de tecido ósseo de ratas com osteoporose.

\section{MÉTODOS}

Todos os procedimentos éticos deste trabalho foram realizados de acordo com a Declaração Universal dos Direitos dos Animais e os princípios éticos da experimentação animal emitidos pelo Conselho Nacional de Experimentação Animal (CONEA), conforme Lei Federal oㅜ 11.794, de 8 de outubro de 2008. O protocolo de pesquisa, obteve parecer favorável da Comissão de Ética em Uso de Animais (CEUA) UniFacid/Wyden em 10 de julho de 2018, conforme protocolo número 10/2018.

Para produção do extrato em gel, o qual foi obtido a partir das folhas frescas da planta; 19,5 gramas de folhas foram lavadas em água corrente e posteriormente colocadas sobre papel-toalha para secagem. Em seguida, elas foram trituradas em liquidificador com $150 \mathrm{ml}$ de água destilada. Após trituração, o líquido obtido foi filtrado em tela de polietileno e depois filtrado em papel filtro qualitativo para a obtenção do extrato aquoso (Figura 1). O extrato aquoso de mastruz apresentou concentração de $130 \mathrm{mg}$ para cada $1 \mathrm{ml}$ de solução. Para obter um extrato em consistência de gel foi efetuada a diluição de $1 \mathrm{ml}$ do extrato aquoso em $10 \mathrm{ml}$ de gel de carbopol, conseguindo assim uma concentração de $13 \mathrm{mg} / \mathrm{ml}$ no extrato em gel de mastruz.

Figura 1 - Separação das folhas, filtragem para obter o extrato aquoso, obtenção do extrato em gel de mastruz pela incorporação de carbopol.

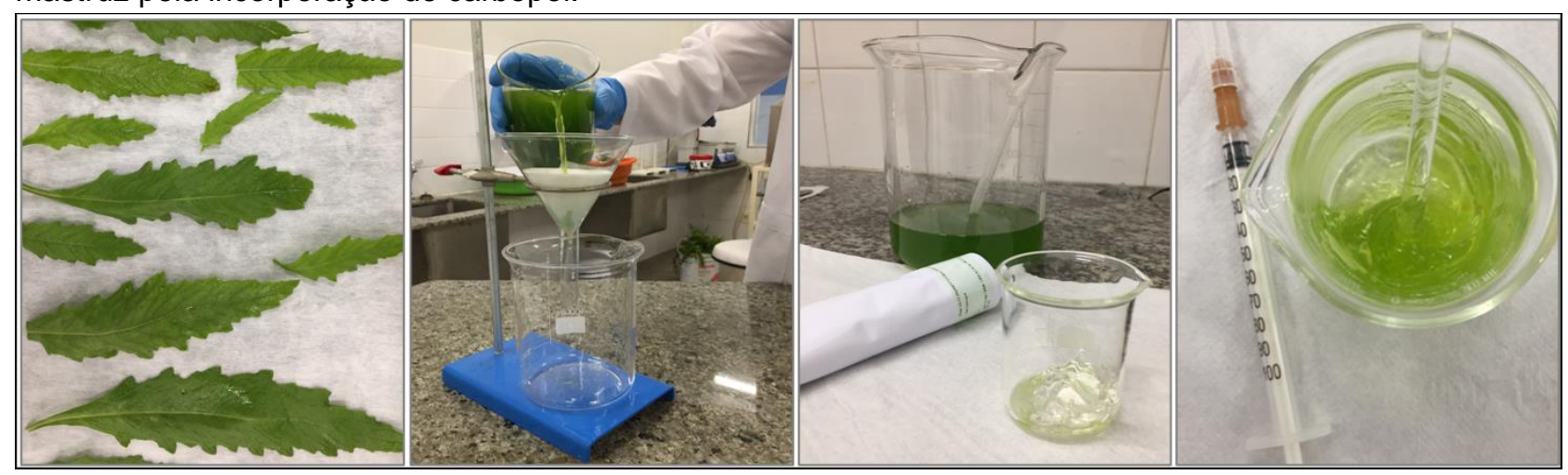

Fonte: Trindade GD, et al., 2020.

A fim de verificar a presença de saponinas no extrato aquoso de mastruz foi feita a pesquisa de saponinas através do Teste Qualitativo de Espuma. Em um tubo de ensaio, foi adicionado 2 gramas do extrato aquoso de mastruz em $10 \mathrm{ml}$ de água destilada e feita sua decocção (fervura) por 3 minutos, após agitado energicamente, no sentido vertical por 15 segundos. A altura da espuma foi marcada no tubo de ensaio após a agitação e verificada 15 minutos depois (Figura 2). 
Para verificação de presença de taninos no extrato aquoso de mastruz foi realizada a pesquisa de taninos através de três testes de identificação, sendo necessários 2 resultados positivos entre eles para confirmação da presença de taninos. O primeiro teste de identificação foi feito com a adição de 2 gotas de $\mathrm{HCl}$ diluído em $2 \mathrm{ml}$ de extrato aquoso de mastruz em tubo de ensaio e após o gotejamento de solução de gelatina a $2,5 \%$, a formação de precipitado caracterizou o resultado positivo do teste. O segundo teste de identificação foi realizado em um tubo de ensaio com $2 \mathrm{ml}$ do extrato aquoso de mastruz mais $10 \mathrm{ml}$ de água destilada e 4 gotas de $\mathrm{FeCl}_{3}$ a $1 \%$ em metanol, o resultado foi positivo para taninos condensados ou catéquicos devido a formação de anel de coloração verde. O último teste foi realizado em tubo de ensaio com $5 \mathrm{ml}$ do extrato aquoso de mastruz adicionado de $10 \mathrm{ml}$ de solução de ácido acético a $10 \%$ mais $5 \mathrm{ml}$ de solução de acetato de chumbo a $10 \%$, sendo o resultado também positivo devido a formação de precipitado esbranquiçado, caracterizando taninos hidrolisáveis no extrato aquoso de mastruz. Com os 3 testes de identificação positivos, pode-se confirmar a presença de taninos no extrato aquoso de mastruz (Figura 2).

Figura 2 - Resultados dos testes de verificação de taninos e saponinas.

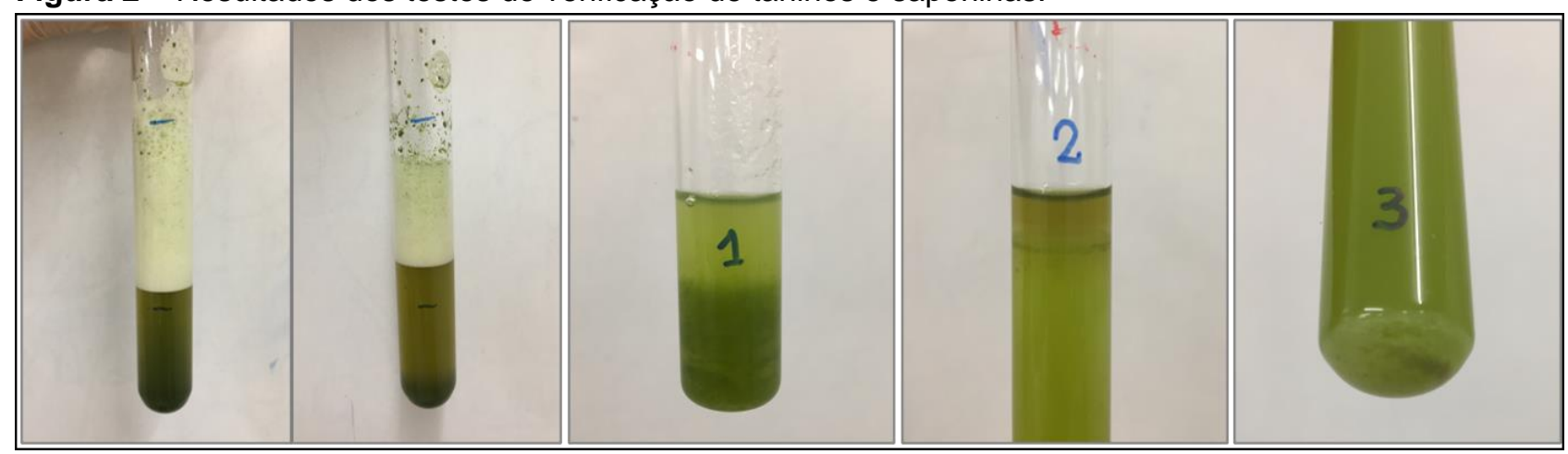

Fonte: Trindade GD, et al., 2020.

Para o ensaio biológico, foram utilizados 12 roedores da espécie Rattus norvegicus, da linhagem Wistar, fêmeas, com 60 dias de idade e peso médio de $300 \mathrm{~g}$, mantidas desde o nascimento no Biotério da Faculdade Integral Diferencial - Facid/Wyden. Os animais foram divididos aleatoriamente em dois grupos de seis animais e acomodados em gaiolas de propileno com boas condições de higiene e alimentados com dieta padrão do biotério, ração (Labina) e água ad libitum.

Após uma semana de adaptação, as ratas foram submetidas à cirurgia para remoção dos ovários (ovariectomia), que foi executada por um médico veterinário. Antes da anestesia, foi administrada para cada animal 1 gota via oral de dipirona sódica $500 \mathrm{mg}$. As ratas foram submetidas à anestesia dissociativa com xilazina e quetamina na proporção de $1: 1$ na dose de $0,1 \mathrm{ml} / 100 \mathrm{~g}$. Após tricotomia e assepsia, foi realizada uma incisão reta transversal na fossa ilíaca de aproximadamente dois centímetros na pele e tecido celular subcutâneo a cerca de um centímetro da linha mediana. A parede muscular foi divulsionada até ter acesso à cavidade abdominal, localizando-se o ovário em meio a uma massa gordurosa. A retirada do ovário foi efetuada após ligadura da extremidade da tuba uterina, seccionando-se entre a ligadura e o ovário. A ferida cirúrgica foi fechada por planos, e todo o procedimento foi repetido do outro lado para a retirada do outro ovário.

Concluído o procedimento cirúrgico, foi injetado via intramuscular $(0,1 \mathrm{ml})$ de pentabiótico para animais de pequeno porte ( $3 \mathrm{ml}$ de $240.000 \mathrm{UI}$ de Penicilinas e $100 \mathrm{mg}$ de Estreptomicina e Diidroestreptomicina por $\mathrm{ml}$ ) e os animais foram colocados em suas gaiolas para a recuperação anestésica.

Após oito semanas (período necessário para o estabelecimento da osteoporose nas ratas ovariectomizadas) foi realizada a cirurgia para produção dos defeitos ósseos (NETTO CC, et al., 2006). Após a pesagem dos animais os mesmos receberam um pré-anestésico (atropina), por via cutânea, na dosagem de $0,04 \mathrm{ml} / 100 \mathrm{~g}$. Passados 15 minutos, foi administrado anestesia dissociativa com xilazina e quetamina (proporção de 1:1) na dose de 0,1 ml/100g. 
Em seguida, foi feita depilação, antissepsia com clorexidina a $2 \%$ e isolamento da área ser operada com campos cirúrgicos estéreis. Uma incisão linear na pele, de aproximadamente $20 \mathrm{~mm}$ de extensão, foi feita no sentido crânio-caudal com um bisturi no 15 . Logo após, a pele músculo e periósteo foram divulsionados para exposição da superfície óssea.

Para produzir um defeito ósseo monocortical, de aproximadamente $2 \mathrm{~mm}$ de diâmetro, na tíbia dos animais, foi utilizado um micromotor cirúrgico, com broca esférica de aço ํo 8 montada e abundante irrigação com soro fisiológico. Nos animais dos Grupo 1, a loja cirúrgica foi preenchida pelo coágulo sanguíneo. Nos animais do Grupo 2, foi feito o mesmo procedimento dos demais animais, porém o defeito ósseo foi completamente preenchido pela formulação à base de gel do extrato de mastruz.

O biomaterial foi inserido na loja cirúrgica com auxílio de agulha e seringa descartável (Figura 3). Em seguida, foi realizada a sutura dos planos. A musculatura e fáscia muscular foram suturados com fio reabsorvível 3-0 e a pele com fio de nylon 3-0. Para terapia antimicrobiana, todos os animais receberam no pós-operatório Pentabiótico de amplo-espectro, via intramuscular profunda em dose única de $0,02 \mathrm{ml} / 100 \mathrm{~g}$.

Os animais foram eutanasiados, transcorrido um período de 30 dias da realização do procedimento cirúrgico, seguindo todos os princípios éticos do COBEA para a dissecação das amostras que foram submetidas à análise histológica. A eutanásia foi realizada com sobredose de anestésico. Os animais receberam a aplicação via intracardíaca de anestésico Tiopental Sódico, na dose de 0,05ml/100g. Após remoção das porções ósseas, os cadáveres foram congelados em freezer e descartados posteriormente pelo técnico responsável pelo biotério da Instituição.

Figura 3 - Ensaio Biológico: Ovariectomia e inserção do biomaterial na loja cirúrgica.

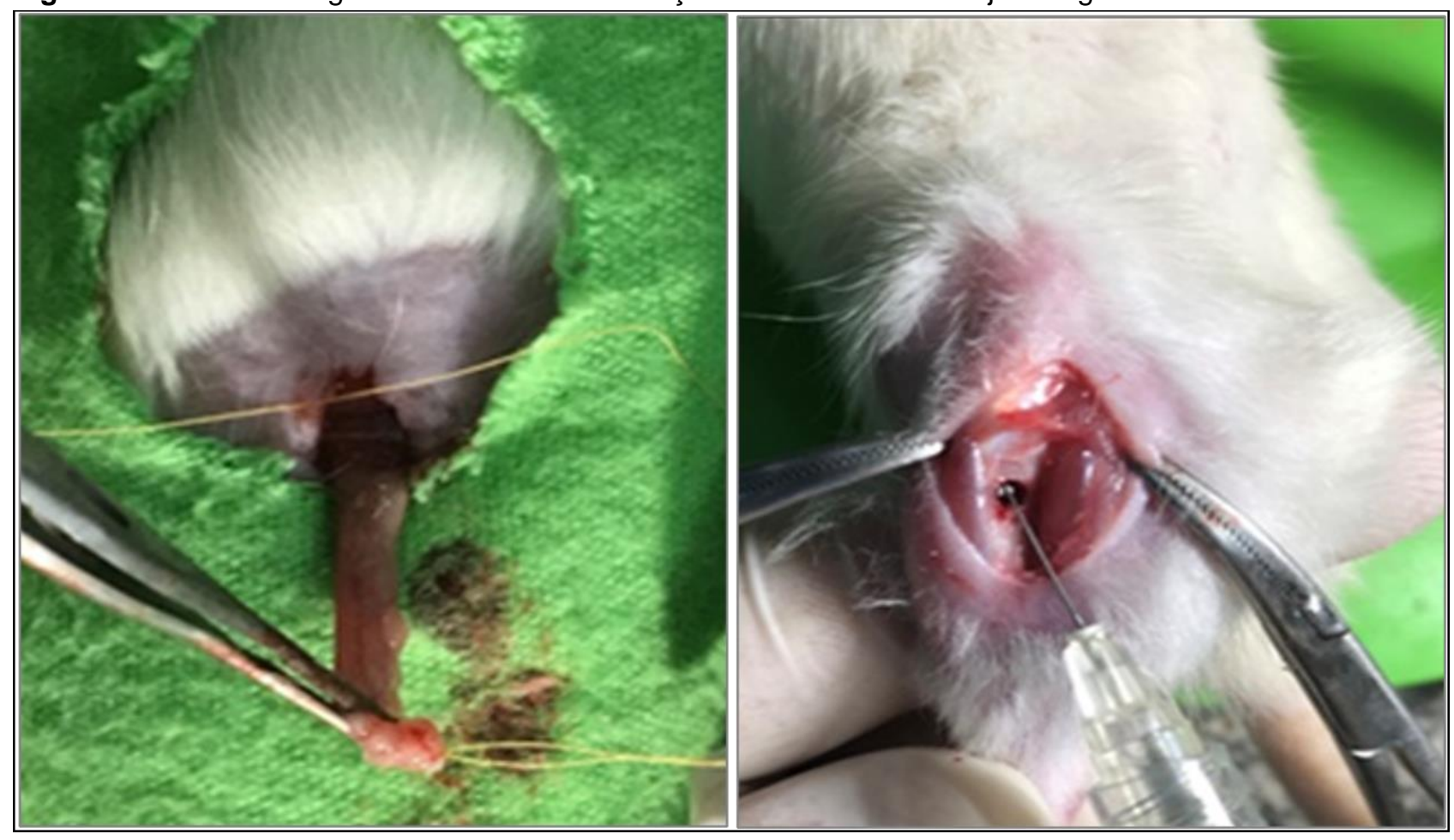

Fonte: Trindade GD, et al., 2020.

Logo após a eutanásia dos animais, procedeu-se a remoção das porções ósseas. Estas foram seccionadas na parte central do defeito cirúrgico, com o auxílio de disco de aço acoplado ao micromotor. As porções ósseas foram separadas em recipientes e identificadas de acordo com o grupo ao qual pertencem, sendo fixadas em formol $10 \%$ por $48 \mathrm{~h}$, e descalcificadas em solução de ácido fórmico $20 \%$. Posteriormente, todas as peças foram submetidas às devidas etapas de rotina laboratorial para coloração com HematoxilinaEosina (H.E.), para posterior estudo histomorfológico em microscopio óptico. 
As lâminas coradas foram numeradas de acordo com o número do animal e grupo ao qual pertencia. A análise descritiva histológica foi realizada com auxílio de microscópio de luz, baseada nos critérios: presença de infiltrado inflamatório e neoformação óssea (tipo de tecido ósseo).

\section{RESULTADOS}

O extrato em gel do mastruz foi produzido e apresentou consistência gelatiniforme e concentração de 13 $\mathrm{mg} / \mathrm{ml}$, permitindo uma adequada utilização nos defeitos cirúrgicos das ratas osteoporóticas. Para confirmação de saponinas na composição do extrato, foi realizada a triagem fitoquímica através do Teste de Espuma, no qual foi observado a permanência de espuma após 15 minutos, caracterizando o resultado positivo para saponinas.

Para triagem fitoquímica de taninos, foram realizados três ensaios, no primeiro teste de identificação, feito com a adição de 2 gotas de $\mathrm{HCl}$ diluído em $2 \mathrm{ml}$ de extrato aquoso de mastruz em tubo de ensaio e após o gotejamento de solução de gelatina a $2,5 \%$, ocorreu formação de precipitado caracterizando o resultado positivo. No segundo teste de identificação, o resultado foi positivo para taninos condensados ou catéquicos devido a formação de anel de coloração verde. No terceiro teste, o resultado também foi positivo devido a formação de precipitado esbranquiçado, caracterizando taninos hidrolisáveis no extrato aquoso de mastruz. Com os 3 ensaios de identificação positivos, pode-se confirmar a presença de taninos no extrato aquoso de mastruz (Quadro 1).

Quadro 1 - Resultados dos testes fitoquímicos.

\begin{tabular}{|c|c|c|c|}
\hline- & Testes & Sim & Não \\
\hline Taninos & Teste de Espuma & $X$ & \\
\hline \multirow{3}{*}{ Saponinas } & Teste de Identificação com HCl & $X$ & \\
\cline { 2 - 5 } & Teste de Identificação com FeCl & $X$ & \\
\cline { 2 - 5 } & Teste de Identificação com $\mathrm{Pb}\left(\mathrm{C}_{2} \mathrm{H}_{3} \mathrm{O}_{2}\right)_{2}$ & $X$ & \\
\hline
\end{tabular}

Fonte: Trindade GD, et al., 2020.

Aos 30 dias pós-cirurgia, os animais do Grupo 1 apresentaram leve infiltrado inflamatório, preenchido por espículas ósseas e trabéculas ósseas delgadas e intercomunicantes, apresentando apenas tecido ósseo primário na maioria dos animais, sem outros achados significantes (Figura 4).

Figura 4 - Fotomicrografia do reparo ósseo aos 30 dias pós-operatório - Grupo 1.

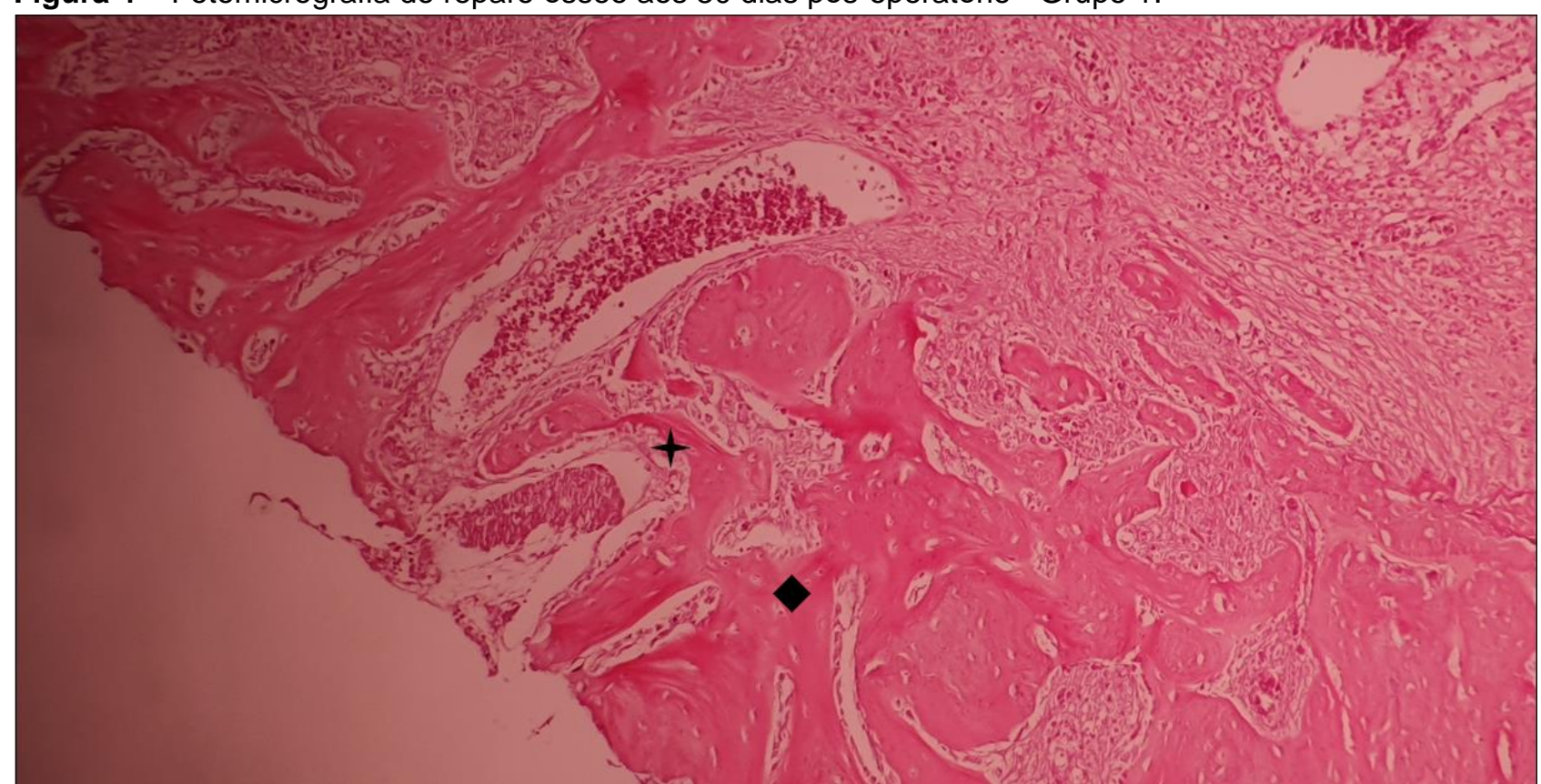

Legenda: + - Espícula Óssea; - Trabécula Óssea. Fonte: Trindade GD, et al., 2020. 
Enquanto, nos animais do Grupo 2, tratados com o extrato em gel de mastruz, pode-se perceber trabeculado ósseo espesso e intercomunicante, constituído por tecido ósseo secundário permeado por tecido ósseo primário, evidenciando uma neoformação otimizada em comparação ao Grupo 1. Também foi possível identificar periósteo com presença de células osteogênicas recobrindo a área do defeito ósseo e ausência de infiltrado inflamatório (Figura 5).

Figura 5 - Fotomicrografia do reparo ósseo aos 30 dias pós-operatório - Grupo 2.

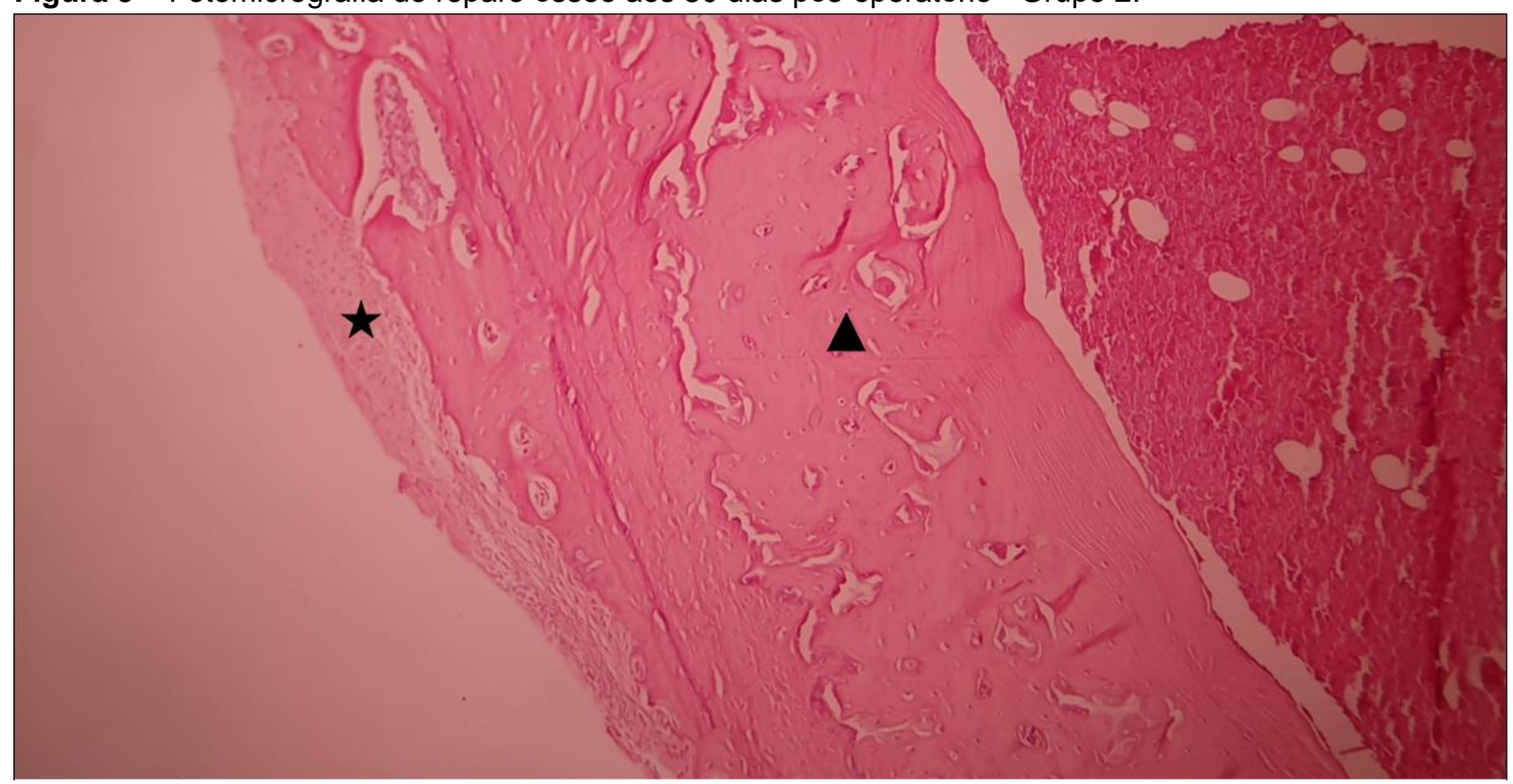

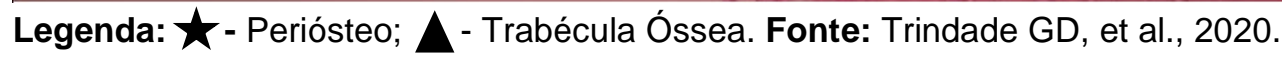

\section{DISCUSSÃO}

A triagem fitoquímica foi realizada de acordo com o Teste Qualitativo de Espuma e os Testes de Identificação, evidenciando a presença de saponinas e taninos, respectivamente, na composição do extrato em gel de mastruz. Tais compostos favorecem uma melhor regeneração óssea e o sucesso do reparo ósseo usando o extrato em gel de mastruz devido suas características biológicas, pois, são agentes importantes no processo de reparo ósseo devido ao potencial antioxidante dos taninos e efeitos estimulantes das saponinas no sistema imune (CASTEJON FV, 2011).

No presente trabalho foi utilizado um modelo de osteoporose induzida por ovariectomia nas ratas, o qual é amplamente utilizado nas pesquisas científicas, e que simulam os efeitos da deficiência de estrógeno no tecido ósseo (CARVALHO DCL e CLIQUET JUNIOR A, 2003; KODAMA I, et al., 2004).

Durante o início da reparação óssea, por causa da instalação do processo inflamatório, ocorre a formação de radicais livres, que em grandes quantidades levam a danos celulares. Por tal motivo, existe a necessidade de o organismo ter antioxidantes para combater os radicais livres, tendo em vista que os compostos antioxidantes podem diminuir o estresse oxidativo (COSTA SO, 2016).

Pesquisas acerca do potencial antioxidante são motivadas devido a ação sobre o estresse oxidativo que condiciona as fisiopatologias do tecido ósseo. Com isso, as substâncias fitoterapêuticas tomam maior relevância devido ao potencial redutor e neutralizador dos radicais livres (ALMEIDA JMM, 2013).

De acordo com Almeida JMM (2013), os taninos, identificados nessa pesquisa por triagem fitoquímica, são frequentemente relacionados ao processo de cicatrização e são encontrados em alto teor na planta, possuindo também atividade antioxidante, sequestrando radicais livres e com isso favorecendo o processo de reparo ósseo (CASTEJON FV, 2011). 
Os compostos antioxidantes agem no metabolismo ósseo de forma direta ou indireta, podendo interferir no recrutamento de células osteoprogenitoras, favorecendo a diferenciação e função osteoblástica, mas principalmente, reduzindo a diferenciação osteoclástica e diminuem o tempo de sobrevidas dessas células, logo ocorre um aumento no número de osteoblastos com consequente aumento da síntese de matriz óssea, deixando o trabeculado ósseo mais espesso e aumentando a qualidade do tecido ósseo (ALMEIDA M, 2007; HA H, et al., 2004).

\section{CONCLUSÃO}

Foi produzido extrato em gel de Chenopodium ambrosioides (mastruz), contendo saponinas e taninos na sua composição. Na metodologia aplicada neste estudo, o extrato obtido apresentou efeitos anti-inflamatórios e osteoindutor, visto que interferiu positivamente na qualidade de osso neoformado de ratas osteoporóticas. No entanto, recomenda-se que sejam realizados novos estudos que oportunizem a caracterização química dos demais compostos presentes no extrato e seus respectivos mecanismos de ação. Assim como a aplicabilidade clínica, a fim de desenvolver um protocolo terapêutico promissor na reparação óssea.

\section{REFERÊNCIAS}

1. ALMEIDA JMM. Avaliação do potencial antioxidante e osteoindutor do extrato do mastruz (Chenopodium ambrosioides L.). Dissertação (Mestrado em Ciências Farmacêuticas) - Universidade Estadual da Paraíba, Campina Grande, 2013.

2. ALMEIDA M. Oxidative stress antagonizes wnt signaling in osteoblast precursors by diverting $\beta$-catenin from $T$ cell factor to forkhead box O-mediated transcription. The Journal of Biological Chemistry. 2007; 282(37): 27298-27305.

3. CARVALHO DCL, CLIQUET JUNIOR A. A Ação do ultra-som de baixa intensidade sobre ossos de ratas osteopênicas. Acta Ortop Bras. 2003; 11: 17-24.

4. CASTEJON FV. Taninos e Saponinas. (Seminário). Programa de Pós-graduação em Ciência Animal. Escola de Medicina Veterinária e Zootecnia. Universidade Federal de Goiás. Goiânia, 2011.

5. COSTA SO. Análise histológica da reparação óssea com utilização de compostos extraídos da semente do urucum em ratos Trabalho de Conclusão de Curso em Odontologia. Faculdade Integral Diferencial Facid|Wyden. Teresina, 2016.

6. FENG X, MCDONALD JM. Disorders of bone remodeling. Annual Review of Pathology, 2011; (6): 121-145.

7. FILHO GB. Bogliolo - Patologia. 8 ed. Rio de Janeiro: Gen, Guanabara Koogan, 2011.

8. $\mathrm{Ha} \mathrm{H}$, et al. Reactive oxygen species mediate RANK signaling in osteoclasts. Experimental Cell Research. 2004: 301(2): 119-127.

9. KODAMA I, et al. Estrogen regulates the production of VEGF for osteoclast formation and activity in op/op mice. Journal of Bone Mineral Research, Hiroshima. 2004; 19(2): 200-206.

10. LESLIE WD, MORIN SN. Osteoporosis epidemiology 2013: implications for diagnosis, risk assessment, and treatment. Curr Opin Rheumatol. 2014; 26(4): 440-446.

11. MARQUES L. Desenvolvimento, caracterização e desempenho biológico de um novo biomaterial de liberação controlada à base de carbonato de lítio aplicado ao reparo ósseo. Tese (Doutorado em Ciências Odontológicas Aplicadas) - Faculdade de Odontologia de Bauru, Universidade de São Paulo, Bauru, 2017.

12. NETTO CC, et al. Efeitos da ovariectomia experimental no metabolismo ósseo de ratas wistar adultas: um modelo para estudo da osteoporose. R. Ci. méd. biol. 2006; 5(3): 231-238.

13. PENHA ES, et al. Effect of Chenopodium ambrosioides on the healing process of the in vivo bone tissue. 2017; 80(11): 1167-1173.

14. PEREIRA SEM, MENDONÇA LMC. Osteoporose e osteomalácia. Tratado de geriatria e gerontologia, Rio de Janeiro: Guanabara Koogan, 2002.

15. PUZIPE KTP. Reparação óssea com o uso do beta fosfato tricálcico na calota craniana de ratos submetidos ao alcoolismo experimental: Análise histomorfológica e histomorfométrica. Dissertação (Mestrado em Ciências Odontológicas Aplicadas) - Faculdade de Odontologia de Bauru. Universidade de São Paulo. Bauru, 2016.

16. SARTORI AR, et al. Comparação do processo de reparo ósseo em tíbias de ratas normais e osteopênicas. Acta Ortopédica Brasileira. 2008; 16(1): 37-40.

17. SCHROEDER JE, MOSHEIFF R. Tissue engineering approaches for bone repair: concepts and evidence. Injury, $2011 ; 42(6): 609-613$.

18. SÉRVIO EML, et al. Cicatrização de feridas com a utilização do extrato de Chenopodium ambrosioides (mastruz) e cobertura secundária estéril de gaze em ratos. ConScientiae S. 2011; 10(3): 441-448.

19. SILVA E. Avaliação da qualidade do reparo ósseo em ratas ovariectomizadas, lesionadas e tratadas com Arnica montana fitoterápica e homeopática. Dissertação (Mestrado em Biopatologia Bucal) - Faculdade de Odontologia de São José dos Campos. Universidade Estadual Paulista, São José dos Campos, 2012.

20. SOARES CD, et al. Chenopodium ambrosioides L. extract prevents bone loss. Acta Cirurgica Brasileira. 2015; 30(12): 812-818. 